\title{
Educación de la memoria desde la literatura:
}

\section{pasado, (re)interpretación del presente y el recuerdo como praxis de formación}

\section{Education of the memory from the literature: past, (re)interpretation}

\section{of the present and the memory as training praxis}

\author{
Marc Pallarès Piquer ${ }^{1}$ y José Vicente Villalobos Antúnez ${ }^{2}$ \\ ${ }^{1}$ Universidad Jaume I de Castellón, España. E-mail: pallarem@uji.es \\ ${ }^{2}$ Universidad de La Costa, Barranquilla (Colombia). Universidad Católica de Temuco (Chile). \\ Universidad de Zulia (Venezuela).E-mail: jvvillalobos@gmail.com villalo4@cuc.edu.co
}
Este trabajo se llevó a cabo en el marco de la una estancia de investigación en la Universitat Oberta de Catalunya. Barcelona, España.

\section{Resumen}

El artículo analiza la memoria relacionada con el tiempo y la historia desde la narrativa contemporánea. Se parte de obras literarias de autores clave para el argumento, se expone que las ideas de la memoria y el tiempo, articuladas con lo histórico, juegan un papel transcendental para la formación de la vida humana como proyecto. El análisis enlaza los conceptos mencionados y forma una unidad experiencial, que amalgama y da sentido a la materialidad de la vida a través de los personajes literarios y de su generalización como experiencia social e individual humana. Desde la narrativa se presentan estos conceptos como unidad, y son considerados por filósofos, narradores e historiadores. Se argumenta la relación entre tiempos vividos, los que se viven y los que quedan por vivir, y se argumenta finalmente que la memoria es una dimensión individual humana, pero que, en su relación con el tiempo, es vivida como un contínuum: es una unidad temporal entre pasado, presente y futuro.

Palabras clave: literatura, educación, memoria, tiempo, interpretación formación

\begin{abstract}
The article presents an analysis of memory in its relation to time and history, from the perspective of contemporary narrative. Taking as a starting point literary works of key authors for the work, such as Cortázar, Borges, Fournier, among others, from the concept of memory it is stated that, from the creation of literature, this idea along with that of time, both are articulated to the idea of the historical fact as past, but taking the latter as a future that flows into the concrete present that is projected into the future as an existential unit, not only of literary characters, but of the memory lived as a present experience. That is why this concept and its praxis play a transcendental role for the formation of human life, this time seen as a project, through literary creation, since it starts from the Bergsonian idea that, if the literary work wishes to be authentic, the author must expose himself as a unit in his feeling as a human being and in the creation itself. According to the analysis made to the authors brought to the study, the researchers manage to link the concepts
\end{abstract}


memory, time and history; these ones, in their experiential amalgamation as an experience, give meaning to the materiality of life not only of the characters involved in the argument, but to their generalization as part of the human social experience. The narrative presents these concepts, according to the researchers, as part of the unit that is the human, an issue that is present in the arguments of philosophers, narrators and historians that were used as pertinent for the study, such as Borges, Heidegger, Nietzsche, Bergson, among others. Through a hermeneutical analysis of the fundamental work for the article, it is understood with Heidegger, for example, that, if one wants to live life, if the "being" wants to "be-together-with" (Mitsein from Dasein), one should stop looking at the past as history, and feel it as part of a flow of experiences that are born, in the past, but that are accentuated in the present, and are projected into the future as becoming without end. It is a continuous time in memory as a way of being of Dasein. Likewise, it is argued with Nietzsche that memory as history is useless for life, because if one wants to feel this, it is unnecessary to look at the past unless one wishes to disassemble oneself from the real human experience; that is, we are facing a continuity of the experience. It is thus possible to see the relationship between the times lived, those that are lived and those to be lived, finally considering that memory is certainly a human dimension, but that, in its relationship with time, it is lived as a continuum; that is, as a temporary unit formed by past, present and future. However, at the end of the argument, the past counts as the livelihood of the present life but also as a projection of future life (Peña, 2019), so it is concluded that the works analysed allow us to establish the course of temporality present inseparably from life itself. Without past there is no present, just as without it, there is no future. This allows researchers to rethink the issue of temporality in everyday life because individual life is combined with social life thus constituting a constant flow of living. Finally, the article establishes that memory is a fundamental dimension of formation in life, since, being Bergson at the right side, every work is part of the author's own temporality that creates it, and therefore, memory, as part from this temporality, permeates human life from the sense of its existence.

Keywords: literature, education, memory, time, interpretation training

\section{Introducción}

La memoria constituye una de las materias primas de la historia; no obstante, en el pasado siglo XX se fue gestando una separación entre ambas. El sociólogo Maurice Halbwachs (1994), fallecido en 1925 en el campo de concentración de Buchenwald, afirmaba que puede haber una historia, pero que existen muchas memorias colectivas ${ }^{1}$, porque el acto de recordar puede convertirse en una de las actuaciones más humanas de aquello que hemos consensuado en denominar como "administraciones públicas", sobre todo cuando de lo que se trata es de rendir homenaje a aquellas personas que sufrieron algún daño en el pasado.

Esta distinción entre memoria e historia propició un conjunto de finalidades diferenciadas que establecieron que la historia, como disciplina, opte por la búsqueda de la verdad. La memoria, en cambio, se consideró que aspira a la fidelidad. A la literatura le corresponde la potestad de morigerar la esfera del recuerdo a partir de una concepción de la memoria como armazón de la realidad de su narrador o sus personajes ${ }^{2}$. Memoria y creación lite-

${ }^{1}$ El propio Maurice Halbwachs $(2004$, p. 6) propone de manera explícita una vinculación entre la memoria y la vida en sociedad, la "memoria colectiva", puesto que "es en la sociedad donde normalmente las personas adquieren sus recuerdos, es allí donde los evocan, los reconocen y los localizan".

${ }^{2}$ Desde la Baja Edad Media, la memoria fue entendida como una fuente de capacidades que, mediante lo sensitivo, conseguía reforzarse, tanto a partir de la vía imaginativa como de la estimativa, esto es, "La memoria en las obras 
raria erigidas en atalaya de confluencia entre rememoración y semiótica (Beltrán, 2018), intersección desde la que se pueden generar recuerdos que no se agoten ni en la coherencia ni en la sinrazón. También es necesario que no ignoren el rigor de la memoria como recorrido que lleva a cabo un trayecto de representación y de resignificación temporal. Hay que tener presente que hablamos de literatura como creación. No obstante, al pasado que se recoge en la memoria se le suele atribuir un sentido de pasividad en cuanto al mundo de vida reconstruido (Zambrano, 2018). Y también se le otorga un sentido activo, pues sirve de catapulta para que, desde lo individual o lo social, se reestructure la vida justamente individual y social.

Sin embargo, si la literatura se quiere expresar de manera auténtica, se debe enfocar desde la simplicidad de lo individual, pues esa es la manera de alcanzar notoriedad y complementación entre el texto literario y el autor del texto: si la obra literaria es auténtica (en sentido filosófico bergsoniano), esta debe enfocarse desde la interioridad y la vida propia del autor: a fin de cuentas, este filósofo piensa que si se quiere ver al autor en sentido profundo, debe hacerse desde la propia vida de aquel.

A partir de la revisión hermenéutica de obras narrativas de las últimas décadas, pertenecientes a culturas muy diversas, el artículo presenta análisis y conclusiones semióticas sobre la memoria, que se basan en el acceso al sentido que hay en estas obras, porque es este sentido el que dispone de la capacidad de reconducirnos hacia una serie de conocimientos vinculados con lo humano.

Contamos con pocas dimensiones tan capaces de revelar el flujo de la vida como la literatura; la persona que crea una ficción literaria renuncia al intento de recluir todos los aspectos de la vida a una visión única. De esta manera, quien lee una novela es quien, finalmente, la comprende; no se convierte en un especialista en el análisis literario, sino en un conocedor del ser humano. Así, la literatura concentra componentes éticos, comunicativos, sociológicos, filosóficos, sociales... que convierten los saberes en interrogantes que retornan en dirección a quien los recibe: este es precisamente uno de los compromisos de la memoria con los propósitos que nos ayudan a entender mejor el pasado, y también con las responsabilidades que condicionan nuestra manera de vivir el presente.

En la novela de Alain Fournier (1913/2004), El gran Meaulnes, el protagonista asevera que ha conseguido localizar el lugar donde suceden las cosas y donde almacenamos la memoria; pero ¿Sabemos cuál es este lugar? ¿Y tenemos la certeza de cómo se llega? En nuestra condición de humanos disponemos de unos sellos (culturales, genéticos, etcétera) de los que nos resulta difícil desprendernos, y no siempre nos ayudan a elucidar ni dónde suceden las cosas ni dónde guardamos todo lo que la memoria va registrando.

En realidad, ¿cómo recurre la memoria a aquello que se ha vivido? A partir de la postura semiótica que toma al signo como punto de inflexión para la creación de sus conceptos, vamos a comprobarlo a través de una aproximación hermenéutica a fragmentos narrativos correspondientes a obras escritas en el siglo $\mathrm{XX}$. Centrar el ámbito de la investigación en una dimensión específica como la memoria nos ha llevado a no determinar un corpus específico; de esta manera, nos referiremos al conjunto de la narrativa leída a lo largo de nuestra vida, circunscribiendo la selección, no obstante, a aquellas obras escritas en el pasado siglo XX. Debido a cuestiones de teoría literaria que escapan de los objetivos de este artí-

pedagógicas de la Baja Edad Media (...) es un proceso racional que tenía su cima y corolario en la contemplación de la verdad donde la inmediatez producía la actualización más acabada del alma” (Vergara, 2012, p. 120). No obstante, el hecho de recordar no se constituía como el objetivo nuclear de la memoria, ya que el propio Vergara (2012,p. 120) asegura que "se trataba de integrar el recuerdo en el alma, de informar al intelecto para comprender la realidad y dirigir la acción al bien". 
culo (llegada de las vanguardias, etcétera), la literatura escrita a partir del siglo XX refleja que el sistema de memoria del sí mismo es la dimensión conceptual que enfatiza la relación recíproca existente entre el sí mismo y la memoria. Y lo hace esencialmente porque la percepción que tiene un individuo de sí mismo es intrínseca a la memoria de su vida. Esto es lo que nos permite observar en estas obras narrativas el sentido que adquiere la memoria a través de sus particularidades. A la estela de ello, la hipótesis de la cual partimos es que cuando la literatura del siglo XX recurre a la memoria lo hace gracias a elementos autónomos que, aunque surjan del tiempo pretérito, no se adscriben por completo a su pertenencia, porque la literatura, como la vida misma, concibe la memoria como un proceso en forma de estructura profunda a partir del cual se pueden interpretar muchas cosas.

A pesar de algunos malos augurios, la novela, hoy, es más necesaria que nunca, porque nos salvaguarda de la uniformidad (y de la tan comentada globalización), porque conserva nuestra conciencia crítica respecto a los avances del mundo y, sobre todo, porque, inmersos como estamos en plena era tecnológica y digital (Pallarès, 2014), necesitamos de la imaginación tanto para comprender mejor la inquietante realidad como para retenerla. En este sentido, podemos alcanzar comprensión del papel de la memoria en la reconstrucción de la temporalidad del autor, pues si bien la memoria sirve de sustento para la reinterpretación de los sucesos acontecidos, se trata de rehacer el mundo de vida del autor de la novela (Munita y Margallo, 2019). Hay casos, como en los que piensa Bergson (2018), que el autor puede poseer una mirada absoluta de la vida, si en su relato recrea la autenticidad de su existencia como persona involucrada en los dramas de la vida real. De lo contrario poseerá una perspectiva parcial y relativa de la vida. Reconstruir la memoria significa pensar el presente de forma auténtica, según Bergson (2018).

\section{La memoria asociativa}

En la actualidad, hay un consenso que acepta que la memoria humana no es una reproducción exacta de experiencias pasadas, sino más bien un proceso imperfecto con multitud de errores y distorsiones (Schacter, Guerin y Jacques, 2011). A partir de estas reticencias. a entender la memoria como una simple reproducción de sensaciones empíricas, se abre la posibilidad de otorgar a la creación literaria la facultad de concebirla (y expresarla) como un conjunto de ideas recreadas en la mente de quien narra los acontecimientos que nosotros leemos. La memoria viene a convertirse, así, en un recorrido con un amplio margen imaginativo, legitimado por las ideas de Herrera (1972), ajustándose al pensamiento aristotélico, concretó este proceso de configuración de la idea a través de la memoria: "porque siendo representada a nuestros ojos alguna imagen [del pasado], pasa la efigie de ella por medio de los sentidos exteriores en el sentido común; del sentido común va a la parte imaginativa, y de ella entra en la memoria, pensando e imaginándose para y en la memoria" (Alcalá, 2016, p. 97). La memoria asociativa es la experiencia del individuo de poder conectar los tiempos de su vida, pues de acuerdo con lo que piensa Heidegger, la forma de la existencia humana se manifiesta en el ser que se inserta en el devenir, en un flujo que va del pasado al presente, y desde este hacia el futuro; es la temporalidad del Dasein, como le llama Heidegger al ser en cuanto existente, pues este discurre su vida en un flujo de vivencias, es decir, en un cúmulo de experiencias de vida que se resumen en el presenten, pero que se proyectan al futuro: es la suma de lo transcurrido y de lo que vendrá, como piensa Carlos Peña (2019).

La asunción del pasado se forja de significados constituidos en el presente, hecho que conlleva un abordaje cualitativo antes que cuantitativo (Hernández y Garavito, 2018). Es decir, cada vez que pensamos en algo concreto, la imaginación nos permite afrontarlo con la 
ventaja de los focos del presente, y aquello que se cuenta no tiene la necesidad de ser un espejo del pasado, sino "una acción del sujeto narrador, una iniciativa que emprende para ir configurando la propia identidad. [...] lo que hace el relato es incorporar ese elemento que ordena y funda la conducta de los individuos a su estructura de funcionamiento" (Cruz, 1993, p. 258). Los hechos recordados no buscan un acuerdo que dependa de la aprobación, sino la descripción de una transición de vivencias basadas en relaciones interpersonales reguladas por el presente, tal y como nos confirma la protagonista de Historia de una maestra:

Cuando vivimos [cosas del pasado] es difícil ser un buen notario. Levantamos actas confusas o contradictorias, según el poso que el tiempo haya dejado en los recodos de la memoria. Por eso [...] me tengo que preguntar si reconstruyo de verdad los sucesos, si registro de manera fiable las sensaciones; es decir, si recuerdo o fabulo [...]. Quizás altero anécdotas, fechas, nombres, pero algo más profundo permanece grabado en la médula del sentimiento. Algo que acaba echando raíces y ramas y se enmaraña a medida que el calor del recuerdo lo hace crecer (Aldecoa, 2006, p. 60).

Tal y como asegura Comellas (2001, p. 32), Platón ya planteó que la imaginación "se forja con imágenes elaboradas a partir de improntas depositadas en la memoria; no copia sino reconstruye por evocación las speciei que entran por los sentidos y se imprimen en el almacén de la memoria". A través de este proceso, la memoria presenta la posibilidad de explicar el mundo renunciando, en buena parte, a la (limitada) concreción dinámica de la verdad y al amplio abanico de dimensiones constructivas de las que esta dispone. Lo recordado se canaliza hacia metas cognitivas a las que no se les exige el estatus de fines, previamente experimentados en carne propia en algún momento, puesto que, como apunta
Ainsa (1997, p. 113), la ficción hace posible que observemos las complejidades y simultaneidades de diferentes percepciones "al verbalizar y simbolizar hechos y problemas que no siempre se concientizan o expresan abiertamente en otros géneros"; en "El entenado", de Juan José Saer, dice Araújo (2013, p. 109) que el pasado, el presente y la memoria se "entretejen en la conciencia de un narrador sesenta años después de los hechos, a la luz frágil de una vela", por eso Saer en la novela afirma que su protagonista se "empeña en materializar, con la punta de la pluma, las imágenes que le manda, no se sabe cómo, ni de dónde, ni por qué, autónoma, la memoria" (Saer, 2005, p. 78). De esta manera, la imaginación hace posible que la creación literaria pueda superar aquella concepción de la memoria que la entiende como un entramado que solidifica el pasado como mero reflejo de los hechos y las cosas (Pereira, Dantas y Suruagy do Amaral, 2018). El narrador de "Queremos tanto a Glenda", de Cortázar, así nos lo recuerda: "la memoria juega con sus depositarios y les hace aceptar sus propias permutaciones y variantes; quizá la misma Glenda no hubiera percibido el cambio y sí, porque eso lo percibimos todos, la maravilla de una perfecta coincidencia con un recuerdo lavado de escorias, exactamente idéntico al deseo" (2003, p. 888).

Recordar algo, aunque devenga un mecanismo de asociación representativa, no necesita avalar su potencialidad por medio de analogías a hechos experimentados. La memoria se ampara entonces en el ámbito de una práctica social (recordada por el narrador y/o los personajes) que concreta la dimensión existencial del pensamiento y la acción, esto es, el despliegue narrativo de la argumentación y la explicación, encargados de confiar en su capacidad para minimizar el abismo latente entre la apelación a los hechos supuestamente experimentados y aquello que pudo suceder algún día ${ }^{3}$. El conjunto de la produc-

${ }^{3} \mathrm{El}$ intento de (re)fundación de la filosofía por parte de Husserl responde precisamente a la necesidad de establecerla como una dimensión científica exacta, en base al análisis de aquellos hechos que se muestran «por y desde sí mismos», que vienen intuitivamente «otorgados» en diferentes e inmediatas evidencias. No obstante, para recuperar 
ción literaria de José Saramago puede ser un ejemplo de esto, ya que el escritor portugués se esforzó en evidenciar que la realidad humana es social antes de ser razonable; por eso en las novelas de Saramago no se encuentra una memoria monolítica, sino un espacio impulsado desde reconstrucciones identitarias en las que las realidades y los ideales (en el caso de Cipriano Algor, por ejemplo, protagonista de La Caverna ${ }^{4}$, este ideal se reduce a pretender ganarse la vida como lo había hecho siempre: construyendo figuras de barro) están en acción permanente, en aquello a lo que denominamos cotidianidad: "Cada día que nace es el primero para unos y será el último para otros, $\mathrm{y}$, para la mayoría, solo es un día", afirma el narrador en otra de las novelas del escritor portugués (Saramago, 2005, p. 34). La memoria asociativa, por lo tanto, como reconoce el narrador de otra novela del premio Nobel portugués (Saramago, 1999: 230) tiene la facultad de incorporar hechos a partir de totalidades que atraviesan la red que caracteriza la existencia y que aseguran una percepción de realidad de la que no podemos distanciarnos: "tenía tendencia a llenar los olvidos con recreaciones de realidad propias, obviamente espurias, pero de cuyos hechos de ocurrencia [al protagonista de la novela] le había quedado tan solo un recuerdo superficial, como el que persiste después del paso de una sombra".

Cuando se reciben estos recuerdos que provienen de la memoria asociativa, lo singular se revela como un espacio vivencial donde aparecen unos hechos que, aunque se mantengan vivos, no se agotan en logicidad, ni tampoco se convierten en un receptáculo pasivo de la vida de los personajes. Podemos comprobarlo en el "El callejón de los milagros", donde, después de lamentarse por haber pasado gran parte de su vida en soledad, hay un personaje femenino que "estaba decidida a ser infiel a su memoria tan rápido como fuera posible" (Mahfuz, 2007, p. 25). Esta especie de ruptura con la memoria no proporciona orientaciones de contenido, se limita a presentar procedimientos argumentales repletos de presupuestos que avalan la imparcialidad en la formación de los hechos: la ausencia de un universal racional y también de contextualizaciones al amparo de concreciones específicas sobre los acontecimientos históricos (Pallarès y Chiva, 2018), en la literatura, así lo permiten: "De tanto que lo había tenido escondido, me parecía que lo vivido no había sido cierto" (Aldecoa, 2006, p. 123). En esta recepción (y reinterpretación) del pasado, es el arte (el género narrativo, en esta ocasión) el que hace posible que la génesis de la casuística sea cartografiada en una encrucijada cognitivo-ficcional que en realidad se configura (o se difumina, según el caso) a medida que la acción narrativa del presente se contrasta con hechos pretéritos; hablamos de unos hechos que ya no tienen la certeza de poder encajar en un orden causa-efecto, por eso los seres humanos no tenemos la posibilidad de recordarlo todo ${ }^{5}$ y nuestra vida, tal y

la conciencia de «nosotros mismos» se hace necesario recomponer el orden de las cosas; y las cosas, como lo recuerda Bodei (2001, p. 14) tienen siempre un halo de alteridad, un halo que "ondea en su estado fluido y al que lo atraviesa la corriente del tiempo".

${ }^{4}$ Saramago (2000) describe en La Caverna un mundo en el que no resulta posible disgregar los hechos históricos y la razón, como propugnan los moralistas, quienes, sea a través de la vía que sea, reducen sus discursos y sus postulados a denunciar la abyección humana.

${ }^{5}$ De hecho, al ser capaz de recordarlo absolutamente todo, el Memorioso Funes de Borges, que reconoce que «Más recuerdos tengo yo solo que los que habrán tenido los hombres desde que el mundo es mundo» (p. 161), pasa por un auténtico calvario, que le lleva afirmar que «Mi memoria es como vaciadero de basuras» (p. 161), y al narrador a sentenciar que «pensar es olvidar diferencias, es generalizar, abstraer. En el abarrotado mundo de Funes [al ser alguien que lo retenía todo en la memoria] no había sino detalles, casi inmediatos» (p. 162). En vez de una inmovilidad física, Funes tiene una fijación de los recuerdos, que se mantienen estancados sin que puedan ser olvidados, lo que castiga a Funes a recordarlo todo, en un estado vital que lo paraliza, rehén de su memoria. El sempiterno recuerdo y la percep- 
como se asegura en "La niebla", tres veces, es una continua y "absoluta falta de recuerdos, [...] que se compone de la suma de esfuerzos para recordar esta carencia" (Gutiérrez, 2011, p.41).

Con la memoria asociativa, el retorno al pasado y la opción de rellenar estas carencias a las que se aludía en "La niebla", tres veces se produce a través de la recuperación de "fragmentos" (y no mediante la integración de un todo). Tal y como ocurre en nuestras vidas, en la literatura estos fragmentos resultan eficaces porque nos hacen (re) vivir un patrimonio existencial que vincula a la trama narrativa con la segmentación de algunos momentos muy determinados. Esto es lo que, en parte, permite caracterizar psicológicamente a los personajes, atendiendo a que, como asevera Corbí $(2017$, p. 111) "la norma de ficcionalizar debe especificar el tipo de interés que despierta el proyecto imaginativo [del escritor/-a]", como puede apreciarse en la caracterización de este abogado de "La última noche", de James Salter, cuya vida "estaba al servicio de los demás [...]. Era bueno en su trabajo. El lenguaje y las técnicas del mismo formaban parte de su ser. Vivía en medio de trastornos y de egoísmo pero siempre protegido por las dos cosas" (2006, p. 58).

En la creación literaria, la concepción Heideggeriana de distinguir el Ser de todo aquello que equivale el Ser, esto es, el siendo ${ }^{6}$, resulta muy efectiva: mientras que en nuestras vidas las dimensiones nos implican en todo lo que somos, porque se convierten en afirmaciones existenciales, en la literatura, el Ser puede quedar fijado como un suceso (o un conjunto de ellos), lo que permite caracterizar a un personaje de una manera particular o hacerlo de otra forma diferente; apréciese esta fijación en un ejemplo narrativo en el que se caracteriza el amor como suceso en "Bullet Park", novela de Cheever (2006, p. 29): "El amor que Nailles sentía por su mujer y por su único hijo era algo así como una descarga ilimitada de un claro líquido ambarino que los rodeaba, los cubría, los protegía y los dejaba aislados pero visibles como el contenido de una gelatina de verduras". Aquí el amor se manifiesta como un hilo conductor entre lo que ha sido el autor a través de su ser como manifiesto de amor: el autor se está refiriendo a lo que Heidegger denomina "el cuidado", es decir, que se es ser en tanto se tiene la capacidad de cuidarse a sí mismo como ser; y el amor nos provee de una manera de cuidarse el ser a sí mismo y a su mundo como contenido del ser (pues no solo es rodeado por seres queridos, que Heidegger llama "ser-con", sino como ser-en-el-mundo).

En contraposición a esta posibilidad de la que dispone la literatura, en nuestras vidas el fundamento acerca del sentido del Ser es previo a cuestiones metafísicas referentes a principios existentes; metafísica que, en realidad, implica que cada acción humana y cada pensamiento se basen en la mera presencia. Este fue uno de los retos que afrontó Derrida, quien, en su metafísica de la différance se preocupó, como apunta Cabot de "una metafísica en la cual la propia ausencia de un principio fijo se pueda convertir en un principio fijo" (2007, p. 111).

La rememoración del pasado, la reafirmación de la memoria y la fuerza trascendental de una aspiración de validez ${ }^{7}$ en el presente, aparecen reflejadas en los textos narrativos a través de un acuerdo antropológico-social

ción totalizadora convierten a $s u$ presente en algo insoportable y le impide anhelar cualquier opción de futuro.

${ }^{6}$ La fenomenología de Heidegger se mantiene, según Villalobos (2017, p. 9) “sobre los pilares de la propia humanidad en el sentido más particular del término: cada ser es ser en la medida que se apropia de su experiencia de vida como ser que está en el mundo siempre siendo".

${ }^{7}$ Fuera de la literatura, al ser incapaces de retenerlo todo en la memoria, cuando la dimensión de validez se diluye en nuestro cerebro y se dispersa entre las pautas sociales y culturales que nos exige nuestro día a día, se va cuestionando el significado propio de esta dimensión de validez. Los residuos de nuestras vivencias pretéritas pueden ser la génesis de algunas de nuestras acciones presentes, pero no su configuración completa. 
entre la historia del personaje y la historia colectiva. Es un acuerdo que, en el caso de no producirse, introduce vacíos narrativos, como se puede apreciar en el siguiente fragmento de "Los pasajeros del tren de la noche" de Fogwill, en el que el vacío está vinculado a un compromiso colectivo que, incluso, llega a poner en duda el sentido de la narración escrita como mecanismo de transmisión que contiene un valor pedagógico, instructivo y atemporal:

Estas criaturas crecen sin saber nada, iguales que los grandes, que saben, pero que andan por ahí sin darse por enterados de lo que estuvo pasando estos años. Por eso nadie los va a enterar, y los chicos van a crecer, van a vivir, van a hacer otros hijos y se van a morir sin saber estas cosas, aunque muchos se las escriban y las guarden para ver si pasados los años a alguien le puede interesar (Fogwill, 1993, p. 69).

En estas circunstancias, la imaginación y la memoria pierden una parte de su fuerza de recreación (Herazo, Valencia y Benjumea, 2018); se reducen a propuestas y creencias que, en todo caso, no disponen de aquella fuerza centrífuga hilvanada gracias a elementos vivenciales vinculantes colectivamente. La memoria se concibe entonces como un elemento extremo de la temporalidad y de nuestro contexto sociohistórico: "La historia, el pasado, es, de este modo, una simple isla en un mar del tiempo henchido de posibilidades para una existencia que se sabe tal y que, sin engaños, se dispone a completarse" (Peña, 2019, p. 120). El pasado completa de esta manera el presente; el pasado, constituido por la memoria, sirve de puente para la vida presente. Esto implica que se requiera de una memoria que no sea constitutiva de ninguna disposición o capacidad general, esto es, más proclive a la constitución mimética, soportada en datos de la experiencia, como apreciamos en "Ravelstein", del canadiense y premio nobel Saul Bellow:

Son muchas las ocasiones en las que necesitamos los datos de la experiencia. Nuestra manera de organizar los datos, que suceden muy de prisa $[\ldots]$, hace ir a gran velocidad las experiencias hacia una comedia peligrosamente ordenada y acelerada. Nuestra necesidad de disposición rápida elimina los detalles que fascinan, paran o retrasan a los niños. El arte es un rescate de esta aceleración caótica. La métrica en la poesía, el tiempo en la música, la forma y el color en la pintura (2000, p.195).

De esta manera, la memoria tiene la posibilidad de salir del campo asociativo para ir socavando márgenes de actuaciones reconstructivas que se centren en los principios del conocimiento, la reproducción y la formación, como puede apreciarse en este fragmento de "La cabeza del cordero", de Francisco Ayala (1993, p. 85) " [...] sin darme otro trabajo que el de ir tomando nota [...] y apuntando en mi memoria los sucesivos detalles que se agregaban para completar mi hipótesis y prestarle la armonía de la evidencia”. En estas ocasiones, la memoria trasciende el curso asociativo de la acción y se condensa en fundamentos que van conformando una memoria que se establece como instrumento de formación de configuraciones vitales integradas en formas individuales y colectivas.

\section{La memoria como instrumento de formación del presente}

Recordar y conservar pertenecen a la constitución humana y condicionan nuestra vida y nuestra formación (Fuente y Basulto, 2018). Draaisama (1998) explica que, desde sus inicios, el ser humano ha ido creando referencias simbólicas de retención de información (desde las pinturas rupestres hasta los álbumes de fotos $\mathrm{y}$, más recientemente, las redes sociales) para mantener recuerdos y para nutrirse del entramado de experiencias que ha ido viviendo a lo largo de los siglos (Madriz, 2019). Sin embargo, acudir a la memoria conlleva la (re)utilización de vivencias en las que el recuerdo tiene que ver con la visualización de un retorno a algo que ya ha sucedido y respecto de lo cual se reconstituye una acción, 
émula de la anterior, pero con un significado reinterpretado. La memoria nos retrotrae algo, que se manifiesta, que nos dice cosas, pero cuyo mundo al que representa es (ya) distinto. Por eso, en última instancia, y siguiendo a Gadamer, hay que tener constancia de que, en palabras de Joaquín Esteban (2002, p.78), "la memoria tiene que ser formada; pues memoria no es memoria en general y para todo. Se tiene memoria para unas cosas, para otras no, y se quiere guardar en la memoria algunas cosas, mientras se prefiere excluir otras. Sería ya tiempo de liberar el fenómeno de la memoria de su nivelación dentro de la psicología de las capacidades, reconociéndola como un rasgo esencial del ser histórico y limitado del hombre".

Cuando recordamos no recurrimos a la línea única de un pentagrama ni llevamos a cabo un resurgimiento cognitivo desarrollado como un simple conjunto de hechos (Rühle, 2019), pues experimentamos un ejercicio que nos (re)constituye en el momento mismo de su manifestación; por eso la memoria necesita ser formada, educada, cada vez que recurrimos a ella. Este requerimiento de instrucción se hace aún más necesario cuando la memoria transita hacia experiencias trágicas, como podemos comprobar en este fragmento de la sensacional novela "La Zona" de Dovlátov:

El revolucionario hace el intento de establecer la armonía universal. Empieza transformando la vida $\mathrm{y}$, a veces, alcanza resultados (...). ¿Qué emprende el moralista en esta situación? También intenta alcanzar la armonía. Pero no en la vida, sino en la propia alma. Mediante el autoperfeccionamiento. Aquí es imposible no confundir la armonía con la indiferencia. El artista sigue otro camino. Crea una vida artificial para completar la realidad vulgar. Elabora un mundo artificial en el que la honradez, la franqueza y la compasión son la norma. Los resultados son trágicos: cuanto más fructíferos son los esfuerzos del artista, más palpable es la ruptura entre el sueño y la realidad (Dovlátov, 1982/2009, p. 64).

Esta necesidad de formación implica que el acto de acudir a la memoria nos aproxime a un resultado, nos presente un(os) recuerdo(s), pero, sobre todo, nos allegue a lo que somos $^{8}$ (ahora, en el presente). Encaminarse hacia la búsqueda de la memoria nos implica, nos compromete y nos permite, como sujetos constituyentes, que, a través del recuerdo, nos convirtamos en sujetos constituidos y que podamos actualizar lo que somos. En cierto modo, en la inmanencia que subyace en el recuerdo es donde continuamos rastreando los diversos procesos de contingencia a los que nos compromete la intersección vivencial entre el pasado y el presente, como afirma Jünger (1989, p. 201): "Cuando recordamos ciertas vivencias sentimos un desconcierto extraño. Quisiéramos volver a disfrutarlas; es como si en su momento hubiésemos olvidado lo más importante. Seguramente es un indicio que nos dice que existe una vivencia absoluta, que en las vivencias empíricas no saborearíamos nunca del todo".

En la literatura, esta intersección puede presentarse bajo el umbral de unos acontecimientos que, inscritos en una trama argumental, son generados a través de síntesis, ya que Iser asegura que "por medio de estas síntesis el texto se traduce en la conciencia del lector, y así el objeto del texto se construye como una correlación de la conciencia por medio de un encadenamiento de síntesis sucesivas" (1985, p. 201). Esto implica que la literatura puede superar las acepciones que entendían la memoria como una pre-estructura de la comprensión; permiten ubicar a la creación literaria en otra cota, que le ofrece la posibilidad de escapar de ciertos condicionamientos ontológicos y presentar una reinterpretación que tiene como principio nuclear la historicidad de la comprensión (Cazzato, 2019).

\footnotetext{
${ }^{8}$ Cuando Sócrates le explicó a Teeteto que la memoria es un regalo premeditado de Mnemosyne para que no se extravíen las creaciones de las musas, pretendió hacer explícito que aquello que el ser humano puede llegar a ser se localiza precisamente en lo sido (Esteban, 2002, p. 69).
} 
La constitución de la memoria como formación y su consecuente representación en la literatura tienen la capacidad de establecer una serie de idiosincrasias del relato que la creación literaria desarrolla en consonancia con los principios de la Poética Aristotélica (así como con aquellos cimientos metafísicos de San Agustín enclavados en la temporalidad). Siguiendo a Ricoeur, lo que se lleva a cabo es la consignación de un orden histórico y un desarrollo de la memoria como formación de la narratividad que se ajustan a la "triple relación (...) entre orden del relato y el orden de la acción y de la vida" (Ricoeur, 1985, p. 9), que es lo que permite tanto la asunción de aquellos hechos que son recordados (en la ficción literaria) como la formación de los efectos secundarios que se derivan: "Y al aceptar de lleno el recuerdo que había estado rondando, volvió a inundarle ahora, sin atenuaciones, todo el desamparo que en aquel entonces había anegado su corazón de niño", podemos leer en "La cabeza del cordero" (Ayala, 1993, p. 117). También es esta triple relación la que convierte a la memoria en el soporte de vivencias renovadas que se configuran en función de la actitud hipotética de los participantes en la acción, por eso al personaje del juez Malone de "Reloj sin manecillas", de $\mathrm{McCu}$ llers, cuando dialoga con su nieto, expone esta noción de memoria como soporte de la acción, pero también como contingencia: “el calor del orgullo le corrió por las venas. Como un espejo, proyectó sus sentimientos hacia su nieto. El amor y la memoria le dejaron el corazón abierto e indefenso" (1940/2010, p. 43).
La memoria se establece como un velo con el que se pueden cubrir determinadas situaciones contempladas como fenómenos existenciales $^{9}$ (Bordoni, 2018), y se adscribe al Daisen resuelto ${ }^{10}$, por eso tiene la facultad tanto de desarrollar unos recuerdos desde los cuales la formación encuentre un cierto grado de resolución como de presentar la posibilidad de renunciar a estos recuerdos: "No me corresponde a mí conservar estos recuerdos, adecuarlos a mis propias palabras, no me toca hablar de ellos o abstenerme de comentarlos, pensé. Y me olvidé de ellos" (Müller, 1982/2010, p. 40), afirma un personaje de En Tierras Bajas; y hay otro personaje a quien, en "La lluvia antes de caer", de Coe (2009, p. 69), "El cielo tan azul de aquellos recuerdos del pasado, milagrosamente conservado entre miles de transparencias, ahora se reducía a una hoja en blanco que no te decía nada". Estos son dos ejemplos del olvido como experiencia que, cuando sucede, no se fragmenta, pues no paraliza la ejecución histórica de la vida de las personas y sus acciones (aunque pueda condicionarlas).

El olvido incluso resulta una auténtica paradoja, ya que, "recordar con detalle [...] implica un poder instrumental en que se ratifica la suspensión ontológica de la desmemoria" (Esteban, 2002, p. 65); memoria y desmemoria como parámetros con esencia aparentemente propia y que, por separado o al unísono, se canalizan en un eslabón del mundo, pero del que no siempre podemos servirnos de manera incondicional.

La memoria determina la formación del presente $\mathrm{y}$, como se ha mencionado ante-

${ }^{9}$ Una de las actividades que se lleva a cabo, en este caso fuera de la ficción literaria, es la de la construcción de espacios físicos como lugares de honra a la memoria de causas trágicas del pasado. En este sentido, en una investigación acerca de los sitios donde se cobija o cristaliza la memoria, Nora (2009, p. 20) afirma que "si habitáramos nuestra memoria, no tendríamos necesidad de consagrarle lugares»».

${ }^{10}$ Es inevitable referirse aquí a la filosofía existencial de Heidegger, que equipara las situaciones a los fenómenos existenciales más relevantes. En este caso concreto, al considerar la memoria como parte constitutiva de la resolución, esta puede convertirse en un eje de formación del ser propio. Se concede así a la memoria la posición de la dimensión de "la situación limitada" de autores como Jaspers (porque proporciona a los personajes literarios una forma posible de realización) y también hace posible que la memoria se proyecte hacia hechos del presente que validen las circunstancias del Daisen no exclusivo en aquellas vivencias evocadas del pasado. 
riormente, "no es memoria en general y para todo" (Esteban, 2002, p. 78), por eso no se fija como una simple conjunción de recuerdos y prescripciones (esto nos ayuda a entender por qué a menudo recordamos haber soñado, pero olvidamos la duración y la materia de dichos sueños), más bien presenta reconstrucciones que, cuando se insertan en la literatura, proponen constituciones de sentido, que fluyen por las narraciones con unas constituciones del yo (ya sean ejecutadas por un narrador o mediante alguno de los personajes) a las que les corresponde su consustancial forma de entorno y alteridad, un sistema de flujo de información a través del cual la historia interactúa en su pretensión por posicionarse en nuestras vidas (Pallarès y Chiva, 2017).

Aunque el pasado condicione la formación del presente, la literatura, en ocasiones, como en este fragmento de "La hija del optimista", nos explicita que "el pasado es impenetrable, y ya no lo podemos despertar. Lo que es sonámbulo es el recuerdo, que volverá con sus heridas desde el otro mundo y exigirá las lágrimas que se merece. Nunca será impermeable" (Welty, 1972/2009, p. 151).

A partir de esta concepción del pasado, la memoria literaria abre las puertas a la prescripción de la formación del presente como eje en el que el pasado designa la casuística portátil del estar allí (Savoia, 2018); de esta manera, lo sucedido en el pasado, la narración no lo presenta como algo existente en sí mismo, sino como un curso y un acontecimiento que se desliza en la mediación comprensiva del ensayo humano del mundo.

\section{La memoria como intérprete}

Cuando hablamos de cómo actúa la memoria estamos condicionados por la trans- formación de una trascendencia desde dentro (Gutiérrez Fresneda, 2018). No obstante, recurrir a la memoria como mero reflejo de la razón estructurada internamente resulta un ejercicio que reduce nuestra actividad cognitiva a la apariencia (Pietrafesa, Alves y Pietrafesa, 2018), por lo menos cuando el acto de recordar se restringe al sentido de la evocación. Es entonces cuando cualquier actividad que implique una praxis vital que no se pueda trascender (y que mantenga su aspiración de objetividad) aferra el flujo existencial humano a la lectura procesual de aquello que ha vivido en el pasado (García Marín, 2018), y también a una descripción del ser que en realidad se revela en su eventualidad (Pallarès y Muñoz, 2017).

La memoria como vía de expresión del recuerdo no es un canal que pueda ser detentado mediante la evidencia o la unificación de la subjetividad, sino una manera de ser (Pallarès, 2019), un habitar, un eje de interpretación estructural que, aunque es inestable, contiene una sustancia existencial enmarcada en el contexto de lo que somos y no en la eventual coyuntura de lo que fuimos ${ }^{11}$. A la trascendencia desde dentro la literatura le aporta vías de trascendencia desde fuera, que la compensan y la completan (Villar, 2017). Si en la memoria asociativa la comprensión del pasado se elucida a partir de significados que pueden proceder de la imaginación (Ayala Carabajo, 2018), y si aceptamos que tenemos memoria para unas cosas y no disponemos de ella para otras (fundamento que en la literatura puede precisar de la fijación de la memoria como eje de formación del presente), se está en disposición de aceptar que la concepción de la memoria no se encuentra totalmente vinculada a su concepto (psicológico, social, antropológico...), sino que se desarrolla en

\footnotetext{
${ }^{11}$ Aun así, este contraste no contendría tributo filosófico sin el hallazgo de la temporalidad no acotada del ser. La realidad, con el contacto de la memoria, se emulsiona en el discurrir de interpretaciones, un fluir que implica que el ser de la verdad como analogía del recuerdo no se erija en presencia objetivada del acontecimiento sino en multiplicidad, en diversidad. Así, la asunción de lo verdadero ya no se canaliza por la obligación incontestable de lo en sí, lo cual significa que la verdad ya no nos presiona con su existencia sino que nos ampara y nos presenta diferentes caminos de interpretación.
} 
base a una fuente de creación activa, esencial y primeramente en la praxis vital, de la que emanan una serie de interpretaciones del mundo. Esto hace posible que un personaje de "Detrás de la boca" tenga la opción de recordar "no con la memoria del encierro [de los hechos del pasado] sino con la del eclipse, aquella [memoria] que se convierte en un acto total" (Gutiérrez, 2007, p. 13).

La fenomenología de Husserl reveló la pluralidad de ontologías y evidenció que el fundamento del mundo no resulta ser el sujeto, sino la virtuosa y unitaria "intencionalidad" (y es precisamente esta intencionalidad la que permite que la memoria se convierta en un acto total, como aparece en el fragmento anterior referido a Detrás de la boca), en tanto que la génesis ontológica inconcreta resulta lícita para el objeto, pero también lo es para el sujeto. Esta intencionalidad es reclamada por la memoria a través de una nivelación entre los umbrales de la vida (donde se encuentran los hechos del pasado) y el mundo presente, que es aquel sobre el cual nos comunicamos y en el que intervenimos (Capella, Cosgrove, Pallarès y Santágueda, 2019), por eso, a pesar de su potestad asociativa, en "Historia de una maestra" el narrador asevera que "la memoria selecciona. Archiva la versión de los hechos que hemos dado como buena y rechaza otras versiones posibles pero inquietantes" (Aldecoa, 2006, p 22), lo que lleva a Asecio (2018, p. 266) a concluir que "Para el escritor, la memoria, el diálogo entre el poder legítimo e ilegítimo, el conflicto ético y la reconstrucción histórica son "obsesiones" (...) tributarias de una verdad elusiva y oculta, que muchas veces permanece en las sombras". La particular intencionalidad de las referencias a los hechos solo sigue estando presente para nosotros "en tanto que mantengamos una distancia con respecto al mundo objetivo desde el horizonte intersubjetivamente compartido de las prácticas comunes, una distancia de la que evidentemente carecen otros seres vivos" (Putman y Habermas, 2018, p. 85), y permite a la memoria habitar en lo que es, otorgándole la función de intérprete.
Si la vida en tanto que vida se mantiene en la perenne búsqueda de su esencia, la memoria ejerce como guía y se despliega en la irrealidad del cambio constante, evocando lo que cree recordar, remitiendo antiguas interdependencias (que pueden ser recuperadas bajo el punto de vista de la imaginación, como hemos visto) y (re)asignando todo lo que le es posible a cada uno de los segmentos de la pluralidad. En base al valor constructivo de la vigencia deóntica, la memoria se refiere al estado de cosas, pero no de la misma manera que lo hacen los enunciados morales, sino a partir de las acciones mediante las que ciertos estados de cosas en nuestras vidas se reditúan intencionadamente (Pallarès y Planella, 2019); la interpretación del mundo, entonces, se focaliza en aquello que es evocado a partir de las huellas, esto es, a partir "de las referencias del pasado significativas inscriptas [...] mediante (re)presentaciones opuestas a las presentaciones sobresignificadas de los discursos históricos, científicos o académicos, constituyendo la puesta en lenguaje de las contradicciones cognitivas presentes en un campo social situado históricamente" (Currie, 2010, p. 69).

La persona en recuerdo en la literatura se configura mediante tramas narrativas que se pueden interpretar desde la construcción de acontecimientos entremezclados para fomentar creativamente los hechos que van a ser interpretados. Esta interpretación no deja de ser una hipótesis, que resulta susceptible de ser avalada a través de una constatación que la confirme como la más posible en base a todo aquello que conocemos (esto es, en función del marco argumentativo de la trama, en la literatura, y a través de otros discursos sociales, si se trata de lavida diaria).

La esencia del tránsito hacia la potencialidad de la memoria se convierte en fundamento de mediación y en elemento de interpretación (Jaramillo y Restrepo, 2018), y agrieta la dimensión concreta de la reducción biunívoca "memoria-plasmación fidedigna del pasado". A pesar de ello, la libertad asociativa de la memoria y su capacidad interpretativa 
no representan un salvoconducto, pues, como se asegura en "Nocturno de Chile", "la vida es una sucesión de equívocos que nos conducen a la virtud final, la única verdad" (Bolaño, 2000, p. 13).

Superando dimensiones como la concepción del psicologismo de Schleiermacher, las pretensiones positivistas o historicistas y la intención fenomenológica (premeditada) de recurrir a los hechos para eludir interrupciones gnoseológicas (Fuentes, 2018), la literatura hace posible que el reto de comprender la memoria se aparte de la dimensión epistemológica para desplegarse como eje de interpretación, es decir, como una manera de ser esencial del ser allí (o del fue allí) pero que se revive aquí, puesto que, sin el sentido interpretativo del presente, la luz del recuerdo puede quedar abocada a pervivir en una noche perpetua.

Así, "se abre la posibilidad de reducir el contenido neutralizador del fenómeno de la interpretación" (Esteban, 2002, p. 116), es decir, se extiende una memoria presentada como ampliación del logos que, sin estar dotada de un carácter ahistórico, facilita que el logos aflore sin limitaciones y que se erija en mecanismo para interpretar la realidad como condición de opción de aprehensión humana e histórica.

\section{Consideraciones finales}

En estas páginas se ha presentado un conjunto de integraciones (y disgregaciones) de la memoria y el presente que se pueden producir en la medida en que la narrativa va calibrando las dimensiones del recuerdo. Y eso fue posible gracias a la literatura que ayuda en la compleja tarea de (auto)descubrimiento.

A pesar de que es aceptado que el recuerdo parte de aquello que sucedió (que está inscripto en el pasado y por consiguiente, no tiene opción de leer el presente), el presente sí puede descifrar el pasado, darle sentido (con la memoria asociativa, con la memoria como mecanismo de formación y con la aceptación de su rol interpretativo), asignarle significados y proyectarlo hacia posibles futuros.

En el presente, el pasado lanza voces y hechos sepultados pero vivos; la memoria renace y se recobra a sí misma, ubicada en una cota más elevada que la del pasado y convertida en sustento de aprendizaje, por eso Prats (2016, p. 43) afirma que "la reconstrucción del pasado consiste en ir rellenando los agujeros que la memoria es incapaz de recuperar". En consecuencia, se puede concluir que la memoria es un proceso social e histórico y no solamente un presupuesto o una capacidad cognitiva. Es la conformación representadora la que termina (re)produciendo (u olvidando) lo representado de una forma particular y en la que aquello que se evoca se presenta como una posibilidad, que posee una disposición con diferentes articulaciones y se despliega en vinculaciones en las que se entra en contacto con el presente.

De la misma manera que la filosofía fue un signo de autonomía de la humanidad (Rombach, 2007), el presente trabajo ha podido confirmar la hipótesis apuntada, puesto que recurrir a la memoria deviene un proceso autónomo que, aunque parta del pasado, se escapa de su pertenencia, porque se concibe como un proceso en forma de estructura profunda a partir del cual se pueden interpretar muchas cosas. Con la memoria, en realidad, nos sumergimos en análisis acerca de la vivencia humana y sobre cómo experimentamos nuestro mundo y nuestra realidad (Pallarès, Chiva, Cabero y Caro, 2018); la memoria se desarrolla como un acontecer del que nadie es patrón. Está condicionada por el peso de nuestra observación, pero se proyecta sin que podamos ejercitar la medida del tiempo, al margen del reloj vital que nos enmarca en un campo sincrónico concreto y que nos ubica en el calendario. A pesar de ello, al recordar aquello que nos atañe, no necesariamente se prescinde del tiempo, por eso el narrador de "Latente" afirma que su protagonista "huye de la idea del tiempo, pero no puede evitar sentir estratos temporales hechos de memoria pasada, de memoria presente y de memoria futura" (Gutiérrez, 2002, p. 34). 
Pasado y presente se encuentran atravesados por la estructuración de la memoria, que hunde sus raíces en secuencias temporales en las que cada vivencia interviene como componente (clarificador, cuando recordamos; deshabitado, cuando es imposible recordar) de una vivencia anterior o como experiencia dispuesta a ser condicionada por otra vivencia posterior. Es decir que, los mecanismos de concordancia intencional que la memoria activa emplazan a las potencialidades que subyacen en la dimensión temporal del entramado de vivencias. Pasado, presente, imaginación, formación e interpretación se avivan en el subsuelo del mundo vital y engarzan los recuerdos a los hechos, les proporcionan autonomía y proyectan nuestra praxis hacia el horizonte de intersubjetividades que pocas veces resultan incólumes. En la literatura, la obra siempre tiene un final; en nuestras vidas, tal vez todo se resume en que llegará un momento en el que simplemente se detendrán las imágenes.

\section{Referencias bibliográficas}

Ainsa, F. (1997). Invención literaria y reconstrucción histórica en la nueva narrativa latinoamericana. En: Karl, Kohurt (Ed.) La invención del pasado. La novela histórica en el marco de la posmodernidad. Frankfurt-Madrid: Centro de Estudios Latinoamericanos de la Universidad Católica de Eichstat.

Alcalá, D. (2016). La influencia lulista en Fray Diego Valdés. Y su análisis desde la hermenéutica analógica, Utopía y Praxis Latinoamericana. Revista Internacional de Filosofia y Teoría Social, 21(72), 95-102.

Aldecoa, J. (2006). Historia de una maestra. Madrid: Alfaguara.

Araújo Fontalvo, O. (2013). La memoria como ficción: Una estética de la historia en Juan José Saer y Germán Espinosa. Alpha, 37, 105-114.

Asecio, M. (2018). Sciascia y la ficcionalización de la realidad. Revista de Humanidades, 37, 261-290.

Ayala, F. (1993). La cabeza del cordero. Madrid: Cátedra [año de publicación del libro original:
1978].

Ayala Carabajo, R. (2018). La relación pedagógica: en las fuentes de la experiencia educativa con van Manen. Revista Complutense de Educación, 29(1), 27-41. https://doi.org/10.5209/ RCED.51925

Beltrán, I. A. (2018). Correspondencias en la epistemología y la filosofía política de Luis Villoro. Análisis y evaluación de una propuesta interpretativa. Tópicos, Revista de Filosofia, 56, 237 272. https://doi.org/10.21555/top.v0i56.977

Bellow, S. (2000). Ravelstein. Barcelona: Edicions 62.

Bergson, H. (2018). Historia de la idea del tiempo. Barcelona: Paidós.

Bodei, R. (2001). La filosofia del siglo XX. Madrid: Alianza.

Bolaño, R. (2000). Nocturno de Chile. Barcelona: Anagrama.

Bordoni, M. (2018). La imitación reconsiderada: $\mathrm{Su}$ función en la infancia temprana. Interdisciplinara, Revista de Psicología y Ciencias Afines, 35(1), 119-136. https://doi.org/10.16888/ interd.2018.35.1.6

Cabot, M. (2007). T. W. Adorno. Balance y perspectivas. Illes Balears: Edicions UIB.

Capella, C., Cosgrove, M. M., Pallarès, M. y Santágueda, M. (2019). Aprendizaje Servicio en la formación inicial docente de Educación Física: Análisis de una propuesta en el contexto norteamericano. Publicaciones, 49(4), 47-65.

Cazzato, S. (2019). Consideraciones sobre los conceptos de historia, comprensión y proceso en la obra de Hannah Arendt. Revista de Filosofía, $36(91), 102-111$.

Cheever, J. (2006). Bullet Park. Barcelona: Emecé (año de publicación del libro original: 1969)

Coe, J. (2009). La lluvia antes de caer. Barcelona: Anagrama.

Comellas, M. (2001). Cualquier memoria es literatura. (Memoria literaria y proceso de la creación). Philologia Hispalensis, 15(2), 31-51.

Corbí, J. E. (2017). Obras de ficción, formas de conciencia y literatura. Crítica, 48(145), 129-145.

Cortázar, J. (2003). Obras Completas I. Barcelona: Galaxia Gutemberg. 
Cruz, M. (1993). Narrativismo. En M. Jiménez Reyes Mate (Ed.), Filosofia de la historia. Madrid: Trotta.

Currie, G. (2010). Narratives and narrators: $A$ philosophy of Stories. Oxford: Oxford University Press.

de Herrera, F. (1972). Garcilaso y sus comentaristas. Madrid: Gredos.

Dovlátov, S. (2009). La zona. Barcelona: LaBreu (año de publicación del libro original: 1982).

Draaisama, D. (1998). Las metáforas de la memoria. Una historia de la mente. Madrid: Alianza.

Esteban, J. (2002). Memoria, hermenéutica y educación. Madrid: Biblioteca Nueva.

Fogwill, R. E. (1993). Los pasajeros del tren de la noche. En R. E. Fogwill (Comp.), Restos diurnos (pp. 141-151). Buenos Aires: Sudamericana.

Fournier, A. (2004) El gran Meaulnes (Trad. P. H. Gefaell Gorostegui). Madrid: Random House (año de publicación del libro original: 1913).

Fuente, F. y Basulto, O. (2018). Una epistemología del género documental para la memoria social en Chile. Cinta de Moebio. Revista de Epistemología de Ciencias Sociales, (61), 12-27. https:// revistas.uchile.cl/index.php/CDM/article/ view/48543/57338 https://doi.org/10.4067/ S0717-554X2017000100012

Fuentes, J. L. (2018). Educación del carácter en España: causas y evidencias de un débil desarrollo. Revista Estudios sobre Educación, 35(2), 353-371. https://doi.org/10.15581/004.35.353371

García Marín, M. E. (2018). La ecosofía: un aporte a la memoria de Pueblo Bello. Revista Lasallista de Investigación, 15(1), 143-151. http:// dx.doi.org/10.22507/rli.v15n1a16

Gutiérrez, M. (2002). Latente. Madrid: Siruela.

Gutiérrez, M. (2007). Detrás de la boca. Madrid: Siruela.

Gutiérrez, M. (2011). La niebla, tres veces. Madrid: Siruela.

Gutiérrez Fresneda, R. (2018). Las destrezas del pensamiento y el aprendizaje compartido para la mejora de la composición escrita. Estudios sobre Educación, 34, 263-281. https://doi. org/10.15581/004.34.263-281

Halbwachs, M. (1994). Les Cadres Sociaux de la
Mémoire. Paris, Francia: Albin Michel.

Halbwachs, M. (2004). Las marcas sociales de la memoria. Madrid, España.: Anthropos.

Herazo, C., Valencia A. y Benjumea, M. (2018). Perspectivas investigativas en el estudio de las industrias culturales y creativas. Kepes, 17, 27-67. https://doi.org/10.17151/ kepes.2018.15.17.3

Hernández, J. D. y Garavito, J. J. (2018). Miradas pedagógicas alternativas: sentidos, juego $\mathrm{y}$ contrahegemonía. Revista Filosofia UIS, 17(2), 247-262.

Iser, W. (1985). L'acte de lectura. Théorie de l'effet esthétique. Bruselas: Mardaga.

Jaramillo, D. y Restrepo, L. (2018). El cuerpo y el tiempo: márgenes del lugar y el no lugar en las experiencias educativas. Teoría de la Educación. Revista Interuniversitaria, 30(2), 23-42. http://dx.doi.org/10.14201/teoredu3022342

Jünger, E. (1989). Radiaciones I. Barcelona: Tusquets.

Madriz, G. (2019). Sentido común y prudencia. A propósito del deslenguado político. Encuentros. Revista de Ciencias Humanas, Teoría Social y Pensamiento Crítico, 09, 41-54.

Mahfuz, N. (2007). El carreró dels miracles. Alzira: Bromera (año de publicación del libro original: 1947).

McCullers, C. (2010). Rellotge sense busques. Pollença: Edicions del Salobre (año de publicación del libro original: 1940).

Müller, H. (2010). En terres baixes. Alzira: Bromera (año de publicación del libro original: 1982).

Munita, F. y Margallo, A. M. (2019). La didáctica de la literatura. Configuración de la disciplina y tendencias de investigación en el ámbito hispanohablante. Perfiles Educativos, 41(164), 154-170.

Nora, P. (2009). Pierre Nora en Les lieux de mémoire. Santiago: LOM Ediciones.

Pallarès, M. (2014). El legado de Paulo Freire en la escuela de hoy. De la alfabetización crítica a la alfabetización en medios de comunicación. Teoría de la Educación. Revista Interuniversitaria, 26(1), 59-76. http://dx.doi.org/10.14201/ teoredu20142615976

Pallarès, M. (2019). Estructuras de acogida, 
progreso y sistema educativo. Una aproximación a partir de la serie The Wire. Arte, Individuo y Sociedad, 31(2): 375-392. https://doi. org/10.5209/ARIS.60635

Pallarès, M. y Chiva, Ó. (2017). La teoría de la educación desde la filosofía de Xavier Zubiri. Opción: Revista de Ciencias Humanas y Sociales, 82, 91-113.

Pallarès, M. y Chiva, Ó. (2018). El lugar del individuo en la era post-postmoderna. Sociedad, educación y ciudadanía tras la postmodernidad. Pensamiento: Revista de Investigación e Información Filosófica, 74(282), 835-852.

Pallarès, M., Chiva, O., Cabero, I. y Caro, C. (2018). El valor educativo de la hermenéutica de Ernst Jünger. Utopía y Praxis, Revista Internacional de Filosofía y Teoría Social, 23(3), 122-138. http://doi.org/10.5281/zenodo.2426878

Pallarès, M. y Muñoz, M. C. (2017). La vigencia de Hannah Arendt y John Dewey en la acción docente del siglo XXI. Foro de Educación, 22, 1-23. http://doi.org/10.14516/fde.443.

Pallarès, M. y Planella, J. (2019). Narrare necesse est: por una pedagogía del relato, CADMO. Fascicolo, 2, 76-99. http://doi.org/10.3280/ CAD2019-002011

Peña, C. (2019). El tiempo de la memoria. Taurus: Santiago, Chile.

Pereira, A., Dantas, B. y Suruagy do Amaral (2018). Os laços entre memória e ideologia: as narrativas da população de rua. Athenea Digital, 18(3), 1-27. https://doi.org/10.5565/rev/athenea.2083

Pietrafesa, J. P., Alves, A. I. y Pietrafesa, P. A. (2018). The Social Division of Labor in Rural Spaces in Brazil Memory and History of the Expansion of Rural Social Movements and Disputes Over Hegemony. Fronteiras, 7(2), 220-224. http:// doi.org/ 10.21664/2238-8869.2018v7i2.p202224.

Prats, E. (2016). Aprendre de lletres. Barcelona: Universitat de Barcelona.

Putman, H. y Habermas, J. (2018). Normas y valores. Madrid: Trotta.

Ricoeur, P. (1985). Temps et récit 3. Le temps raconté. París: Seuil.
Rombach, H. (2007). El presente de la filosofía. Barcelona: Herder.

Rühle, M. (2019). Educación para la adaptación. Actualidad de la "teoría de la pseudocultura" de T. W. Adorno en tiempos del aprendizaje permanente. Bajo Palabra. Revista de Filosofia, 21(2), 97-108.

Saer, J. J. (2005). El entenado. Buenos Aires, Argentina. Seix Barral.

Salter, J. (2006). La última noche. Madrid, España: Salamandra.

Saramago, J. (1999). Tots els noms. Barcelona: Edicions 62 (año de publicación del libro original: 1997).

Saramago, J. (2000). La Caverna. Barcelona, España: Edicions 62.

Saramago, J. (2002). L'home Duplicat (2005). Barcelona: Edicions 62 (año de publicación del libro original: 2002).

Savoia, T. (2018). La scrittura nella didattica della lingua straniera. Cadmo, 2, 115-119.

Schacter, D. L., Guerin, S. A. y St. Jacques, P. L. (2011). Memory distortion: An adaptive perspective. Trends in Cognitive Sciences, 15, 467-474.

Vergara, J. (2012). La memoria en las obras pedagógicas de la Baja Edad Media. Bordón, 64(4), 111-122.

Villalobos, J. V. (2017). La investigación educativa y la fenomenología de M. Heidegger. Opción: Revista de Ciencias Humanas y Sociales, 33(83), 7-12.

Villar, E. (2017). La anagnórisis en la literatura juvenil y sus intenciones socializadoras, Opción: Revista de Ciencias Humanas y Sociales, 82, 298-321.

Welty, E. (2009). La filla de l'optimista. Barcelona: Edicions 62 (año de publicación del libro original: 1972).

Zambrano, E. L. (2018). Prácticas pedagógicas para el desarrollo de competencias ciudadanas. Revista Electrónica de Investigación Educativa, 20(1), 69-82. https://doi.org/10.24320/ redie.2018.20.1.1409. 